\title{
A Comparative in Vitro Study of Power Output Deterioration over Time Between Ho:YAG Laser Fibers from Different Manufacturers as a Function of Deflection and Power Input
}

\author{
Andreas Bourdoumis $^{\mathrm{a}} \quad$ Panagiotis Christopoulos $^{\mathrm{b}} \quad$ Nirmal Raj $^{\mathrm{c}}$ \\ Artemis Fedder $^{\mathrm{d}} \quad$ Noor Buchholz ${ }^{\mathrm{e}}$

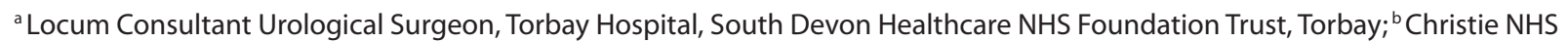 \\ Foundation Trust, Manchester; ' Department of Medical Physics, Royal London Hospital, Barts Health NHS Trust, London; ${ }^{\mathrm{d} B a r t s}$

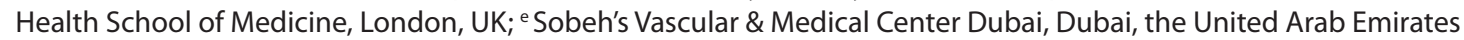

\section{Key Words}

Lithiasis • Laser treatment • Ureteroscopy • Holmium laser

\begin{abstract}
Objectives: To investigate the performance of laser fibers from 6 major manufacturers in vitro and to identify the effect of time and angulations $\left(180^{\circ}\right.$ and $\left.0^{\circ}\right)$ on fiber power output. Materials and Methods: Overall, 36 single-use fibers were used. Each was tested with an energy input of 0.8, 1.4 and 2.0 Joules. A power detector measured power output after 1, 5, 10 and 15 minutes for three 15-minute cycles of continuous use. For the first 2 cycles, the fiber was bent to $180^{\circ}$ with the use of a pre fabricated mould. Analysis of the data was performed by ANOVA and Tukey's test when the results were significant amongst groups. Statistical significance was deemed $p<0.05$. Results: No fiber fracture occurred. There was no significant difference in output at 15 minutes of continuous use at $0^{\circ}$ and $180^{\circ}$. The reduction in energy output at the 15 th minute of continuous use at $180^{\circ}$ was not significant for any fiber type or initial input. Only output differences between the fibers proved to be significant $(p=0.001)$.
\end{abstract}

\section{KARGER}

Fax +4161306 1234

E-Mail karger@karger.ch

www.karger.com
(C) 2015 S. Karger AG, Basel

1015-9770/14/0091-0012\$38.00/0

Accessible online at:

www.karger.com/cur
Conclusion: Fiber fracture and decline in performance is not due to deflection and continuous use. Frictional forces that occur between the fiber tip and the stone fragments may be responsible.

Copyright $\odot 2015$ S. Karger AG, Basel

\section{Introduction}

Technological advancements have contributed vastly to the medical profession and continue to be at the forefront of progress and innovation in medical science. Laser technology is a fascinating field with numerous applications in endourology, especially transurethral prostate and stone surgery. A very rapid development of laser technology imposes a need for up-to-date information about the characteristics of different laser instruments and fibers. The type of laser fiber used is central to the safety and efficiency of laser application. Knowledge of 


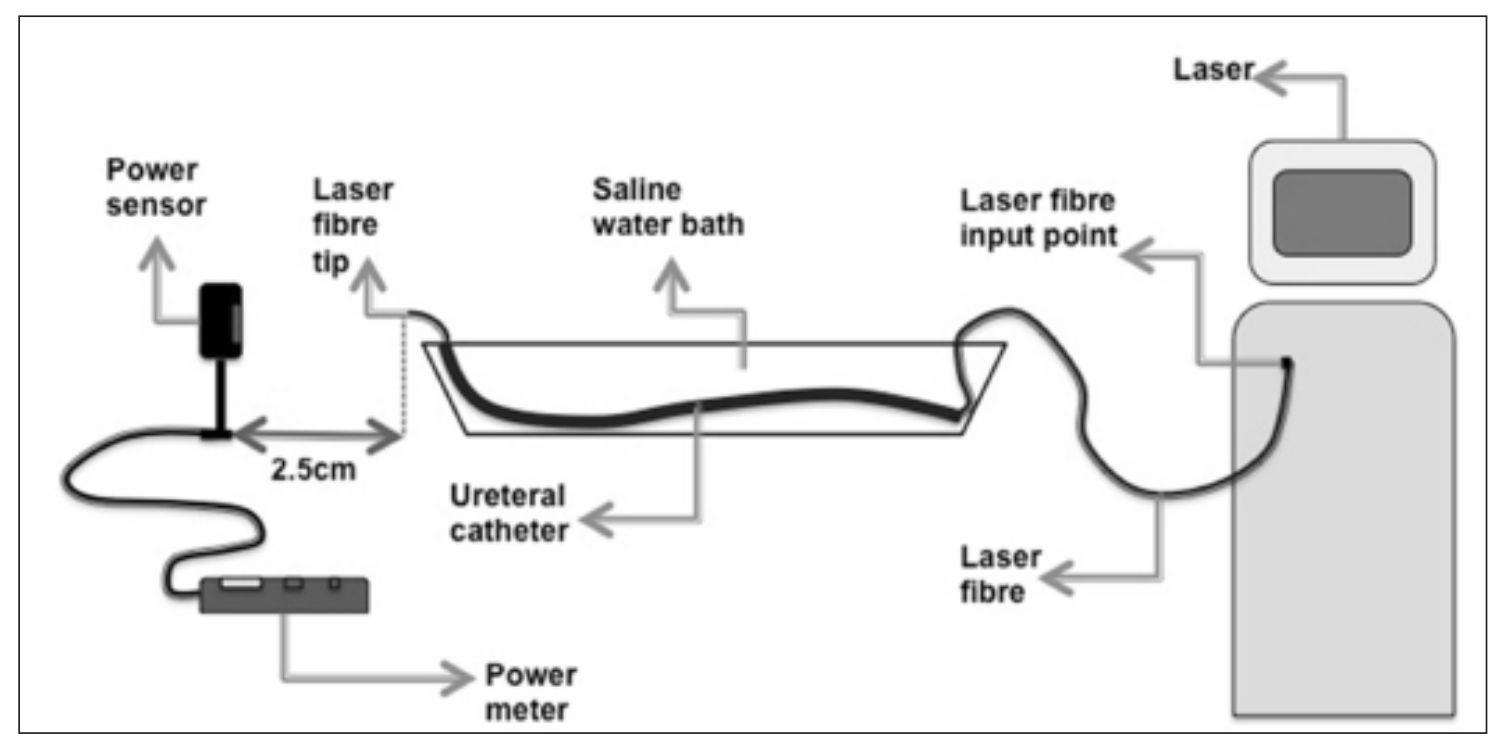

Fig. 1. Schematic of experimental set-up.

the physical properties of fibers, its functions and limitations, as well as its potential is necessary for the practicing urologist. With ongoing research and development, the industry has produced various types of fibers according to application. In the field of laser lithotripsy, all the major manufactures have produced laser fibers ranging from 200-500 $\mu \mathrm{m}$, both disposable and reusable, with subtle modifications in design and functional parameters.

There are numerous reports that address the issue of fiber durability relative to efficiency. Our study aims to provide insight concerning the efficiency of optical fibers subjected to angular deflection, especially with respect to power output deterioration over time. It has been postulated that increasing laser power of a deflected fiber may produce fiber failure and consequent transmission of energy through the ureteroscope, with risk of instrument damage and patient injury [1]. We have conducted a comparative in vitro study of Holmium:YAG (Ho:YAG) fibers from 6 different manufacturers by in vitro simulating actual flexible ureterorenoscopy conditions, in order to investigate the interaction of time and deflection on power output.

\section{Objectives}

The aim of this experiment was to investigate the performance of different fibers from the industry in vitro and to identify the effect of time and $180^{\circ}$ and $0^{\circ}$ bend configurations on fiber power output.

\section{Materials and Methods}

In-vitro tests were carried out, using single-use Ho:YAG laser fibers that were kindly supplied by 6 major manufacturers (Boston scientific $^{\circledR}$, Cook Medical $^{\circledR}$, AMS $^{\circledR}$, EMS $^{\circledR}$, iSurge $^{\circledR}$ and Dornier $\left.^{\circledR}\right)$. The experimental set up consisted of reproducing ureteroscopic lithotripsy conditions in a dry lab. A new fiber was used for each three cycles at the bent configuration and straight configuration. The fiber was introduced into a ureteral catheter submerged in a saline water bath, mimicking the ureteroscope working sheath. The fiber and catheter were stabilized by using gauzes at specified points such that maintained the set up in a stable state. In particular, it was appreciated that in order to maintain a stationary laser fiber, wet gauze should be placed near the front end of the fiber and at the end of the ureteral catheter. The fiber tip was exposed such that the beam could be directed to the power sensor. The exposed tip was placed $2.5 \mathrm{~cm}$ away from the power sensor, as a minimum safety distance to prevent damage to the device. Positions of all instruments used were marked on the table so that stability would be maintained. The power sensor is connected to a power meter from which power output readings were taken. The aiming beam remained switched on in order to ensure that the laser fiber was pointing steadily at the center of the power meter throughout the trials, as preliminary calibrating measurements showed large variation and sharp decreases in power output readings when the laser beam moved away from the center of the power sensor. A schematic of the experimental set-up is shown in figure 1 . The power detector was used to measure the power output after 1, 5, 10 and 15 minutes for three 15-minute cycles of continuous laser pulse. For the first two 15-minute cycles, the laser fiber was subjected to a bent configuration $\left(180^{\circ}\right)$ with a diameter of $25 \mathrm{~mm}$. This configuration was maintained by fitting the ureteral catheter with the fiber into a pre fabricated mould with constant shape (fig. 2). Each of the fibers was tested with an energy input of $0.8,1.4$ and 2.0 Joules. Keeping the initial energy input constant they were subsequently retested with the same angulations for another 15 min- 

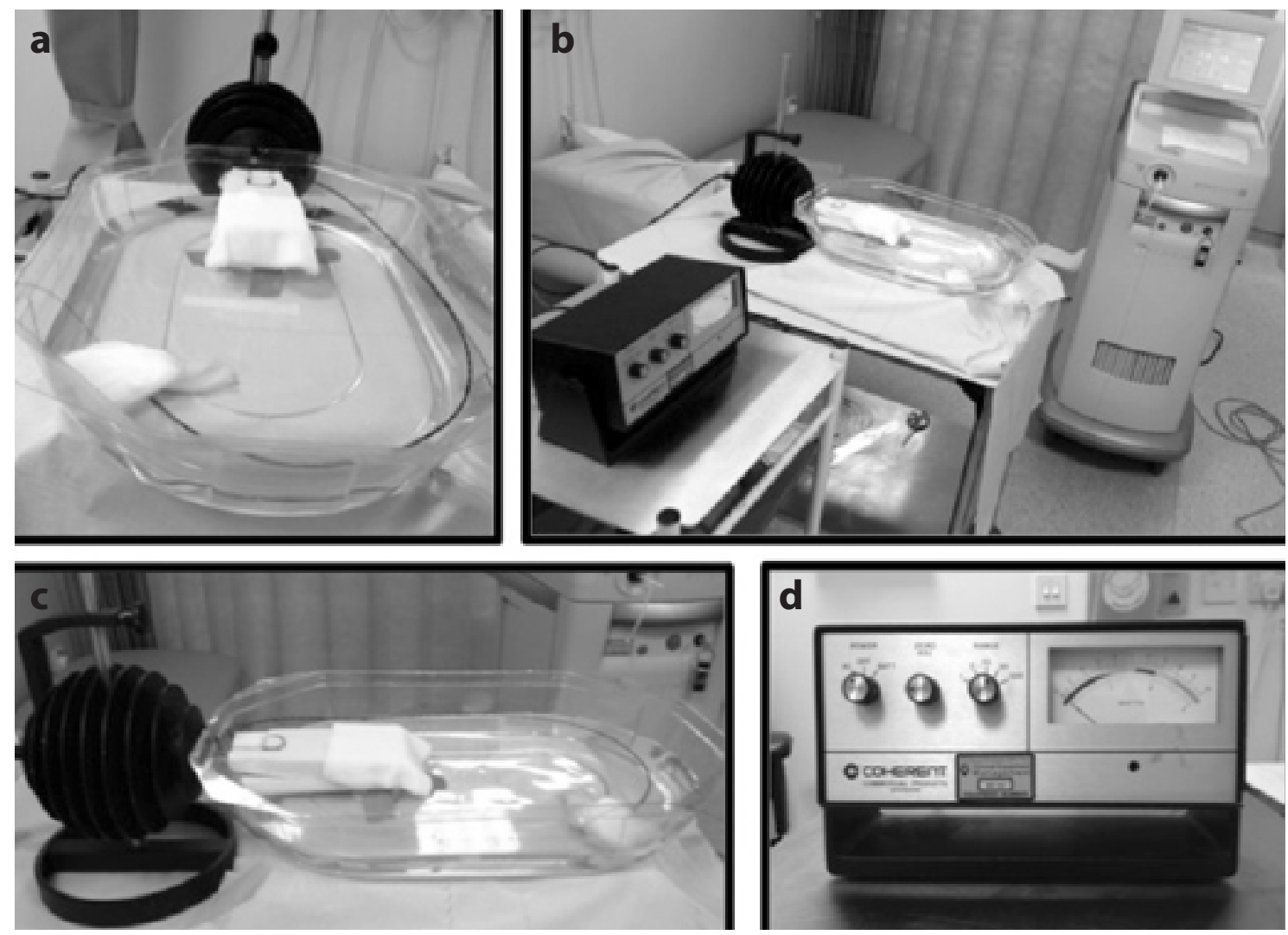

Fig. 2. Clockwise from top left: (a) Saline bath with laser fibre, catheter and power sensor set-up, (b) Experiment set-up, (c) Side view of set-up, and (d) Coherent analogue power meter.

utes. For the last 15-minute cycle, the fiber was straightened and power output readings will be taken, for a total of 45 minutes continuous use of a single fiber for a particular power setting. Each measurement was repeated twice per power setting, giving results for 6 fibers from each manufacturer. Overall, 36 new, single-use fibers were used. In order to be free of any commercial bias and avoid any conflict of interest, the results were anonymized and presented as data from manufacturers $a, b, c, d$, e and $\mathrm{f}$.

Primary end-points of the experiment were to investigate power output and fiber deterioration as a function of continuous energy pulse on a bent fiber. The efficiency of the individual fiber on said conditions was a secondary end point. Analysis of the data was done using analysis of variance (ANOVA) and Turkey's honest significance test when the results of ANOVA were significant amongst groups. Statistical significance was defined as $\mathrm{p}<0.05$ for all tests and comparisons between variables.

\section{Results}

The results of the measurements for all fibers are shown in table 1 . No fiber fractures occurred during testing of 36 fibers from 6 different manufacturers in total.
The initial efficiency of each fiber at $180^{\circ}$ for all three energy input settings was calculated. The various means of energy output in relation to input of all the fibers in the first minute are shown in table 2. No statistical significance was found for the interaction between type of fiber and energy input. In addition, the interaction between type of fiber and energy input did not have any statistically important effect on the energy output ( $p=$ $0.139)$. The reduction in energy output at the $15^{\text {th }}$ minute of continuous use at $180^{\circ}$ was not found to be statistically significant $(\mathrm{p}=0.541)$ for any fiber or initial energy input. The interaction in this time interval between these 2 parameters (type of fiber and energy input) was not significant either $(\mathrm{p}=0.088)$. This was valid for all the fibers and all the initial energy output settings.

Equally to the last of the first 15 minutes of continuous use at $180^{\circ}$, the difference in energy output at 15 minutes of the second round of continuous use was not statistically significant $(p=0.185)$ and no statistically significant interaction was seen between or independent 
Table 1. Actual results of measurements for all fibers, on bent and straight configuration, at $1,5,10$ and 15 minute intervals

\begin{tabular}{|c|c|c|c|c|c|c|c|c|c|c|}
\hline $\begin{array}{l}\begin{array}{l}\text { Fiber } \\
\text { number }\end{array} \\
\end{array}$ & Manufacturer & $\begin{array}{l}\text { Energy Input } \\
\text { (Joule) }\end{array}$ & E1-180 (1) & E1-180 (5) & E1-180 (10) & E1-180 (15) & E-0 (1) & E-0 (5) & E-0 (10) & E-0 (15) \\
\hline 1 & $\mathrm{a}$ & 8 & 7,78 & 7,77 & 7,75 & 7,75 & 7,83 & 7,82 & 7,81 & 7,81 \\
\hline 2 & $\mathrm{a}$ & 8 & 7,86 & 7,8 & 7,77 & 7,76 & 7,84 & 7,76 & 7,79 & 7,79 \\
\hline 4 & $\mathrm{a}$ & 14 & 13,29 & 13,17 & 13,16 & 13,15 & 13,32 & 13,19 & 13,17 & 13,17 \\
\hline 5 & $\mathrm{a}$ & 20 & 19,27 & 19,72 & 19,75 & 19,68 & 19,26 & 19,75 & 19,72 & 19,68 \\
\hline 6 & $\mathrm{a}$ & 20 & 19,31 & 19,3 & 19,3 & 19,27 & 19,3 & 19,3 & 19.28 & 19,28 \\
\hline 10 & $\mathrm{~b}$ & 14 & 13 & 12,75 & 12,6 & 12,5 & 12,5 & 12,5 & 12,5 & 12,5 \\
\hline 11 & $\mathrm{~b}$ & 20 & 18,5 & 18 & 18 & 18 & 17,5 & 17,5 & 17,75 & 17,5 \\
\hline 12 & $\mathrm{~b}$ & 20 & 17,5 & 17,4 & 17,5 & 17,5 & 17 & 17,5 & 17,6 & 17,6 \\
\hline 13 & $\mathrm{c}$ & 8 & 5,6 & 5,6 & 5,7 & 5,7 & 5,6 & 5,6 & 5,55 & 5,55 \\
\hline 14 & $\mathrm{c}$ & 8 & 6,9 & 6,8 & 6,8 & 6,8 & 6,8 & 6,8 & 6,85 & 6,9 \\
\hline 15 & $\mathrm{c}$ & 14 & 11,5 & 11,5 & 11,5 & 11,5 & 11 & 11,1 & 11,1 & 11,1 \\
\hline 20 & $\mathrm{~d}$ & 8 & 7,1 & 7,1 & 7,1 & 7,1 & 7 & 7 & 7 & 7 \\
\hline 21 & $\mathrm{~d}$ & 14 & 12 & 12 & 12 & 12 & 12 & 11,75 & 11,75 & 11,75 \\
\hline 22 & $\mathrm{~d}$ & 14 & 12,25 & 12,25 & 12,25 & 12,25 & 11,75 & 11,75 & 11,75 & 11,75 \\
\hline 23 & $\mathrm{~d}$ & 20 & 17,5 & 17,25 & 17,25 & 17,25 & 17,5 & 17,25 & 17,25 & 17,25 \\
\hline 24 & $\mathrm{~d}$ & 20 & 17 & 17 & 17 & 17 & 17,25 & 17 & 17 & 17 \\
\hline 25 & $\mathrm{e}$ & 8 & 6,05 & 6,03 & 6 & 6 & 6,1 & 6,05 & 6 & 6 \\
\hline 26 & $\mathrm{e}$ & 8 & 6,03 & 6,03 & 6 & 6 & 6,05 & 6,05 & 6 & 6 \\
\hline 27 & $\mathrm{e}$ & 14 & 10,45 & 10,45 & 10,45 & 10,4 & 10,5 & 10,5 & 10,5 & 10,5 \\
\hline 28 & $\mathrm{e}$ & 14 & 10,45 & 10,45 & 10,45 & 10,4 & 10,4 & 10,4 & 10,4 & 10,4 \\
\hline 29 & $\mathrm{e}$ & 20 & 15,15 & 15,1 & 15,1 & 15,1 & $\begin{array}{l}10,4 \\
15,3\end{array}$ & 15,3 & 15,25 & 15,25 \\
\hline 30 & $\mathrm{e}$ & 20 & 15,2 & 15,15 & 15,15 & 15,1 & 15,25 & 15,2 & 15,2 & 15,2 \\
\hline 31 & $\mathrm{f}$ & 8 & 6,11 & 6,1 & 6,1 & 6,1 & 6,13 & 6,14 & 6,14 & 6,14 \\
\hline 32 & $\mathrm{f}$ & 8 & 6,13 & 6,13 & 6,11 & 6,11 & 6,11 & 6,11 & 6,1 & 6,1 \\
\hline
\end{tabular}

variables (fiber and energy input) $(\mathrm{p}=0.302)$. Identical statistical significance was identified, with slightly different $p$ values, when the efficiency was tested at $0^{\circ}$ angle at the first minute and for all time intervals thereafter. In order to test whether the energy output of the fibers varies with the time of usage, a Repeated Measures ANOVA test was used for the measurements at the first and $15^{\text {th }}$ minute of usage. No statistical significance in the difference of energy output was found for the single parameter time $(\mathrm{p}=0.275)$, meaning that the energy output did not seem to be reduced significantly with the $180^{\circ}$ setting for the first 15 minutes of the experiment. Differences between the combination of variables time-fiber ( $\mathrm{p}=$ $0.343)$, time-energy input ( $\mathrm{p}=0.259)$, or time-fiber-energy input $(\mathrm{p}=0.185)$ were equally not statistically sig- nificant. Similar results were obtained with the $0^{\circ}$ setting. A schematic representation of these results can be seen in the following schemes for each of the initial energy input settings (fig. 3 and 4 ).

The differences in the energy output of the various fibers proved to have a statistical significance $(\mathrm{p}=0.001)$. Post hoc analysis of these results using the Turkey's test in order to look deeper into the significance of the parameter fiber in particular has shown that there is a statistically significant difference between the fibers from manufacturer $\mathrm{c}$ and manufacturers $\mathrm{a}(\mathrm{p}=0.035), \mathrm{b}(\mathrm{p}=$ $0.005)$ and $e(p=0.036)$. There is a statistically significant difference between the fibers from manufacturer $b$ and manufacturers $e(p=0.027)$ and $f(p=0.016)$. No other significant difference was found between the other fibers $(\mathrm{p}>0.05)$. 


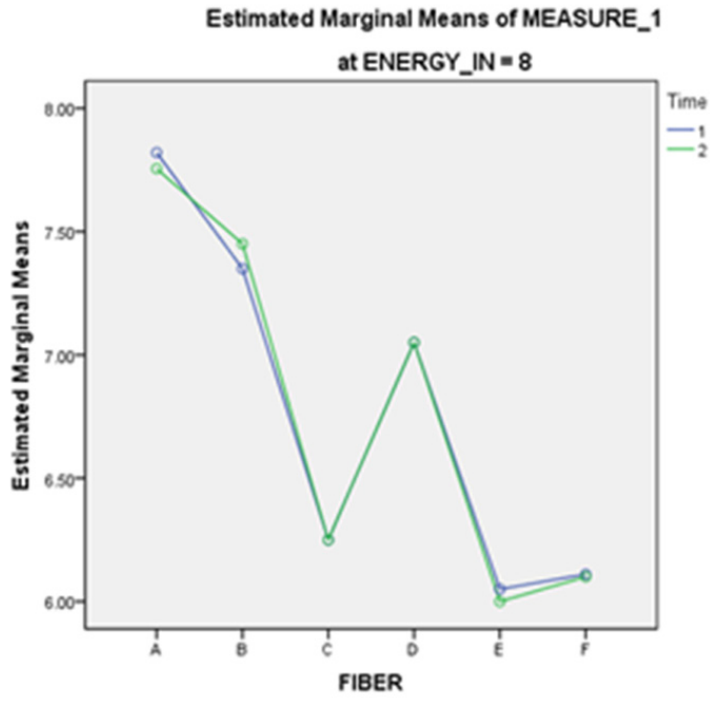

Estimated Marginal Means of MEASURE_1

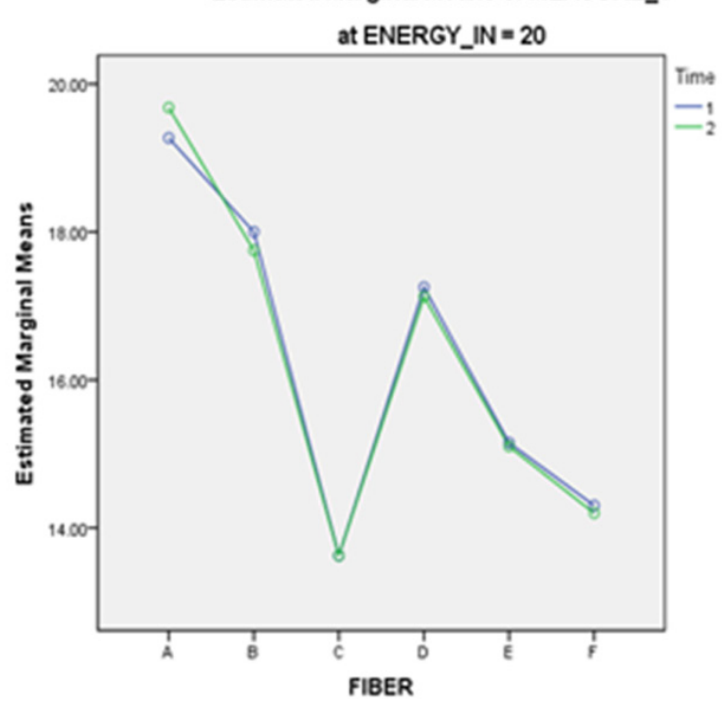

Estimated Marginal Means of MEASURE_1

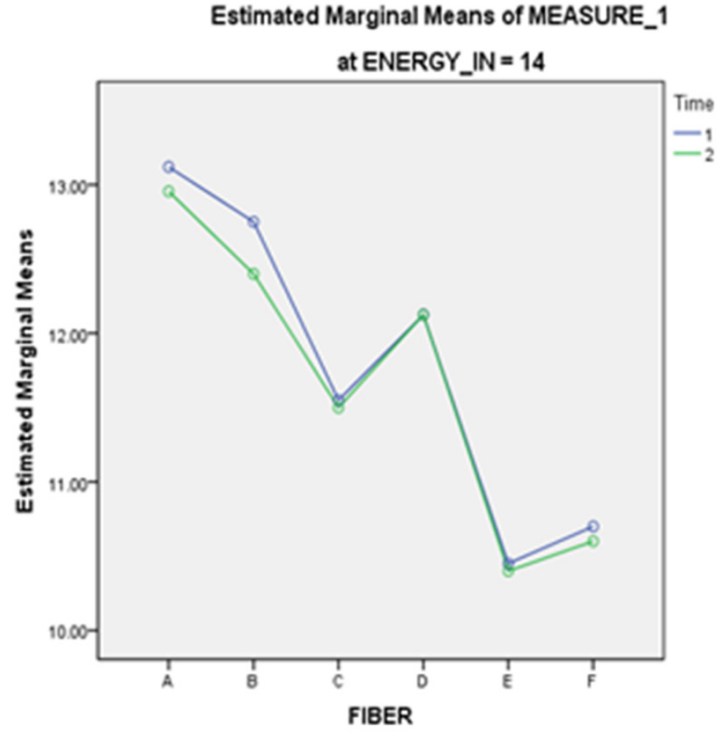

Fig. 3. Schematic representation of the results for change of energy output over time at $180^{\circ}$ by ANOVA test at the first and $15^{\text {th }}$ minute of usage (Time 1 (blue): $1^{\text {st }}$ minute, Time 2 (green): $15^{\text {th }}$ minute) for each of the initial energy input settings.

\section{Discussion}

Research in the field of Ho:YAG lasers and single-use laser fibers is very much prevalent, due to the fact that the Ho:YAG laser has become the medical preference in laser lithotripsy for urinary tract calculi. In our endeavor to identify possible relationships between continuous use of laser fibers at high energy settings and at a bent angle, we did not identify any statistically significant difference. In a previous study by Knudsen et al. [1], that used similar methodology to the present experiment identified deflection as the principal factor for fiber fracture, especially during lower pole ureteroscopy due to thermal breakdown and laser-energy transmission to the endoscope. Following experimental testing, Mues et al. [2] concluded that commercially available fibers show great differences regarding size, flexibility and resistance to thermal breakdown with bending. It was suggested that extreme manipulation and bending of fibers, especially those with small core size, would result in damage at the 

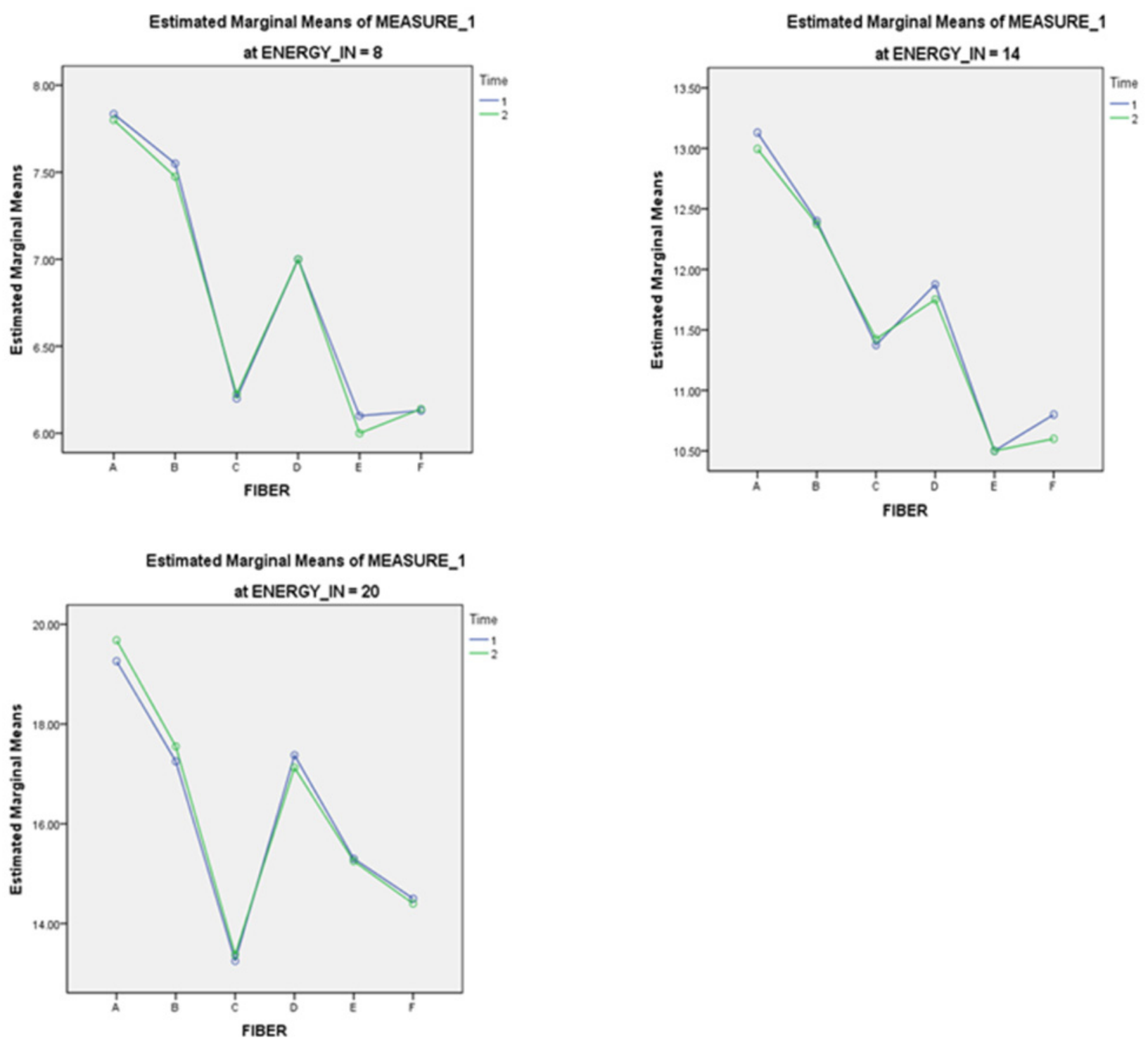

Fig. 4. Schematic representation of the results for change of energy output over time at $0^{\circ}$ by ANOVA test at the first and $15^{\text {th }}$ minute of usage (Time1 (blue): 1st minute, Time 2 (green): $15^{\text {th }}$ minute) for each of the initial energy input settings.

bend site, and cause damage to the ureteroscope as well, due to laser energy travelling through the cladding. In a subsequent report, the same group looked specifically at comparing the durability of the tip of the fiber between manufacturers and concluded that only fibers used on artificial stones suffered burn back at the tip [3]. Interestingly enough, the authors also discovered that the initial fiber output out of the box was less than stated by the manufacturers, which is also in keeping with our findings. It was speculated that incorrect handling and damage in manufacture would influence fiber failure rate. In the same report, failure was not attributed to manipulation of the fibers alone, but mainly in conjunction with the Ho:YAG laser. Ho:YAG laser energy is more likely to damage plastic coating on fibers than are visible wavelengths because of the higher absorption coefficient of plastic in the mid-infrared spectrum [4]. This was further supported by research carried out by Khemees et al. [5], who evaluated the use of 100 new $240 \mu \mathrm{m}$ single-use Ho:YAG laser fiber for flexible ureteroscopy. Their results and testing again highlighted that fiber decay did not occur with bending alone, but only when in use with 
Table 2. Means for the various settings of the experiment at $180^{\circ}\left(1^{\text {st }}\right.$ minute)

\begin{tabular}{lccll}
\hline $\begin{array}{l}\text { Fiber } \\
\text { manufacturer }\end{array}$ & $\begin{array}{l}\text { Energy input } \\
\text { (Joule) }\end{array}$ & $\begin{array}{l}\text { Mean } \\
\text { output }\end{array}$ & $\begin{array}{l}\text { Std. } \\
\text { Deviation }\end{array}$ & $\begin{array}{l}\text { Number of } \\
\text { measurments }\end{array}$ \\
\hline a & 8 & 7.82 & 0.06 & 2 \\
& 14 & 13.12 & 0.24 & 2 \\
b & 20 & 19.27 & 0.87 & 2 \\
& 8 & 7.35 & 0.21 & 2 \\
& 14 & 12.75 & 0.35 & 2 \\
c & 20 & 18.0 & 0.70 & 2 \\
& 8 & 6.25 & 0.92 & 2 \\
& 14 & 11.55 & 0.07 & 2 \\
d & 20 & 13.625 & 2.29 & 2 \\
& 8 & 7.05 & 0.07 & 2 \\
& 14 & 12.125 & 0.18 & 2 \\
e & 20 & 17.25 & 0.35 & 2 \\
& 8 & 6.05 & 0.73 & 2 \\
& 14 & 10.45 & 0.24 & 2 \\
f & 20 & 15.15 & 0.61. & 2 \\
& 8 & 6.11 & 0.75 & 2 \\
& 14 & 10.70 & 0.86 & 2 \\
& 20 & 14.30 & 0.49 & 2
\end{tabular}

the Ho:YAG laser and in stone fragmentation. The authors clearly stated that "painting" of the stone with the fiber rather than drilling it was used as the stone fragmentation technique of choice; Nevertheless, varying degrees of fiber tip damage were identified and recorded.

According to our findings, we believe that it is the physical manipulation and handling of the fiber upon entry into the working channel and friction during lithotripsy, especially during contact with the stone fragments, contributing to damage of the fiber tip. By extension, this diminishes fiber output and efficiency, as well as increasing the risk of fracture and damage to the ureteroscope. Indeed, preliminary unpublished results from ongoing comparative in vivo study at our institution support this statement. In particular, it will be most interesting to investigate the relationship between energy output decay from the fiber with real-time surgical lithotripsy parameters, such as time to fragmentation, power input, frequency, total number of pulses and deflection.

The only statistical significance that was identified was related to differences in output between fibers from the individual manufacturers. However, this was not the primary focus of this experimental set up, as greater numbers of fibers with more controlled conditions and blind randomization would be required in order to draw any safe and useful conclusions regarding comparative efficacy.

\section{Conclusion}

The results of our in vitro study show that fiber fracture and decline in performance is probably due to factors other than deflection and continuous use, even in power settings rarely used in everyday surgical practice. We believe that this is largely due to the frictional forces that occur during lithotripsy as a result of the interaction of the fiber tip with the stone fragments. To support our hypothesis, further experimentation is under way, testing the output of the fibers from the same manufacturers after use in real ureteroscopic lithotripsy conditions in vivo.

\section{References}

1 Knudsen BE, Glickman RD, Stallman KJ, Maswadi S, Chew BH, Beiko DT, Denstedt JD, Teichman JM: Performance and safety of holmium:YAG laser optical fibers. J Endourol 2005;19:1092-1097.

2 Mues AC, Teichman JM, Knudsen BE: Evaluation of 24 holmium:YAG laser optical fibers for flexible ureteroscopy. J Urol 2009; 182:348-354.
3 Mues AC, Teichman JM, Knudsen BE: Quantification of holmium:yttrium aluminum garnet optical tip degradation. J Endourol 2009; 23:1425-1428.

4 Nazif OA, Teichman JM, Glickman RD, Welch AJ: Review of laser fibers: a practical guide for urologists. J Endourol 2004;18: 818-829.
5 Khemees TA, Shore DM, Antiporda M, Teichman JM, Knudsen BE: Evaluation of a new 240- $\mu \mathrm{m}$ single-use holmium:YAG optical fiber for flexible ureteroscopy. J Endourol 2013;27:475-479. 